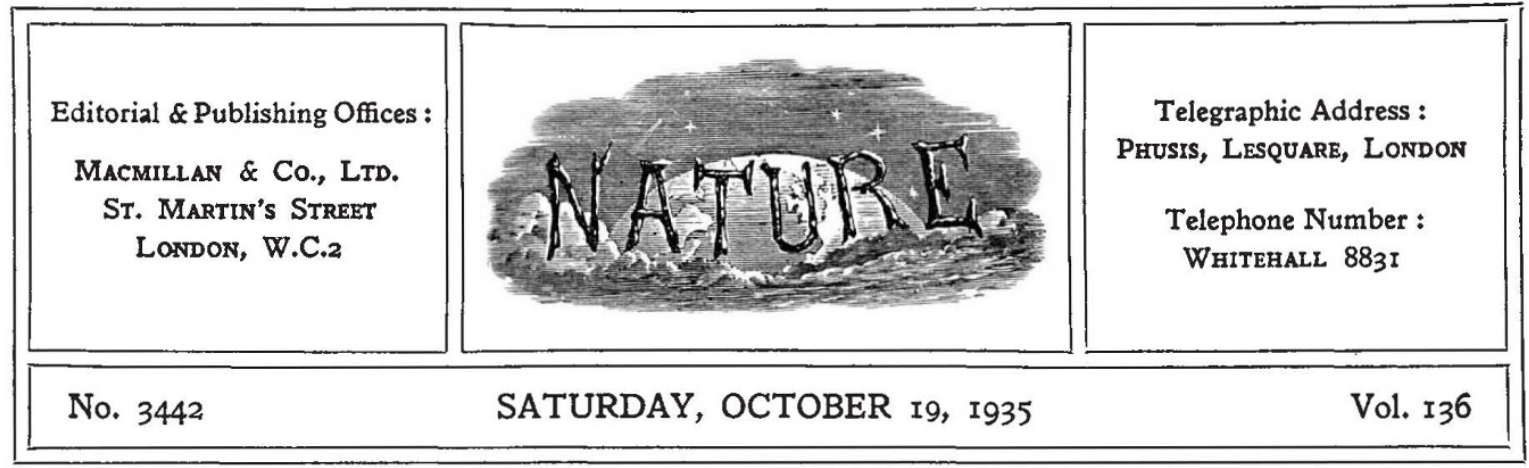

\title{
Preservation of Game Animals of the British Empire
}

A STRAIGHT problem faces the rulers of every part of the British Empire: Is the wild fauna to be left to take its chance at the hands of a native population which has been accustomed to kill without restraint, and in face of the steady encroachments of agriculture, commerce and sport, or is it to be shielded for its own sake and for the sake of posterity? And everywhere the answer is that it must be shielded. Thus a second and more difficult problem is born : To what extent and intensity must protection be carried? For it need scarcely be said (in spite of protection's ultra-enthusiasts) that where a clash arises between wild fauna and human survival or progress, mankind and not its unwitting opponents must have the backing of the State.

Rational legislation for the protection of wild animals (and the protection of the people) must, therefore, endeavour to arrange for preservation without undue multiplication where an animal is already on the down-grade, and for opportunities of destruction-falling far short, it may be hoped, of extinction-where an animal is interfering with the reasonable progress or comfort of humanity. There are few countries in which such rational legislation is in force; for even in lands of longstanding civilisation like our own, where conditions favour detailed and accurate observation, no biological controversies are more strenuous and more indeterminate than those relating to the economic values and the need for preservation or destruction of some of the commonest species. If that is so, how can it be hoped to plan rational laws in the outlying parts of the Empire, where sometimes the need of immediate action seems to be greatest, and where at the same time the balanced knowledge upon which action should be based is least available. Tentative legislation, the effects of which are closely watched and which may be modified at the shortest notice, is the experimental way; but a better way if time allows is to begin by making particular efforts to gather and collate all the information bearing upon the wild fauna in its own relations of numbers, distribution and multiplication, and in its relations to the various activities of humanity, native and non-native. The latter method, with its field surveys and statistics, is being increasingly employed, as every issue of the Journal of the Society for the Preservation of the Fauna of the Empire shows; it is exemplified on the best standard in a report just published by the Government of Northern Rhodesia*. The author is Capt. C. R. S. Pitman, game warden in Uganda, whose annual reports on the game of the Protectorate make one of the most interesting and valuable records of the wild life of Africa, and who carried out the Northern Rhodesia survey and investigations in 1931-32 under instructions received through the Secretary of State for the Colonies.

Since the conditions in Northern Rhodesia are fairly representative of conditions in many countries in process of colonisation, the report carries implications of more than local significance. The most general of these is that game, on the whole, has shown a marked decrease in recent years, and that this decrease is progressive, in spite of the fact that a few species have, during the same period, increased enormously in numbers. Natural agencies, as well as man, have contributed to the decrease. Capt. Pitman attributes it, in the first

\footnotetext{
* A Report on a Faunal Survey of Northern Rhodesia, with especial reference to Game, Elephant Control and National Parks. Pp. xii + $500+x x x i i+11$ maps. (Livingstone, N.R. : Government Printer London: Crown Agents for the Colonies, 1935.) 78. 6d. net.
} 
place, to the great rinderpest epidemic of thirty to forty years ago, which over vast areas wiped out the ungulates, particularly buffalo, eland, lechwe, waterbuck, bushbuck, pig and warthog. Before the stock had had time wholly to recover, the Great War came along, and slaughter for the food of the forces again reduced it "practically to vanishing point" in certain of the provinces. From this disaster most of the species have never recovered, and in their reduced numbers incessant harrying by natives armed with muzzle-loading guns (of which nearly 25,000 have been registered by natives) has caused a progressive decline, and in many localities has brought species to that paucity of numbers which is the forerunner of extinction. Finally, the coming of the railway and the development of mining areas have led to the death of several hundred thousand herd at the hands of Europeans.

The general result is that from districts here and there in which they were once common, species are disappearing: where Broken Hill now stands was once one of the best hunting grounds for the greater kudu, the rhinoceros is all but gone from North-Eastern Rhodesia, the blue wildebeest has vanished from the Awemba district, the lechwe from Kawambwa, game generally from the Fort Rosebery District.

Nevertheless, Northern Rhodesia still remains a land well-stocked. An effort to estimate the numbers of game animals, even though it be regarded as only roughly approximate, is full of interest. Amongst the rarer forms are the giraffe (300 individuals), black-faced impala (500), rhinoceros $(1,500)$, yellow-backed duiker (about 1,500 ), blue wildebeest $(2,000)$, hippopotamus $(3,000)$; while at the other end of the scale are species such as zebra $(50,000)$, buffalo, roan antelope, Lichtenstein's hartebeest, common duiker (all with about 60,000 individuals), and, far and away the most abundant of all, the black and red lechwes (Onotragus) numbering 150,000 and 250,000 respectively. The last two species make up nearly half the total ungulate population of about one million, and this, equally distributed, would average about four individuals to the square mile, or approximately the density of the human population throughout the colony.

In this mass of varieties and of numbers, only some half dozen species appear to be able to stem the current of decline, and only three to make headway against it. The ability to withstand an almost universal tendency depends upon different factors in relation to these select animals and is of great significance from an ecological point of view. Thornicroft's giraffe and Cookson's wildebeest owe their present numbers to the co-operation of the local native authorities in protecting these last representatives of particular races, rather than to any natural power of resistance. The lechwe antelopes have been from time immemorial subjected to great slaughter intensified by a system of extensive driving. In spite of statements to the contrary, Capt. Pitman states that great drives still take place, but yet there is no sign of falling numbers, and this can be attributed only to the enormous annual increase of the lechwe herds. The tsessebe antelope (Damaliscus lunatus), curious in its distribution because in Barotse it is abundant on the right bank of the Zambezi and completely absent from the left, has not only been able to withstand the general influences, but has actually increased in numbers from hundreds to thousands in post-War days; and this would appear to be due, first, to its habit of keeping in small herds averaging 20-50 individuals, and secondly to a characteristic shyness (or wisdom) which keeps it well out of range of the muzzle-loaders of the natives.

The other two successful species, buffalo and elephant, have multiplied simply because they are large, dangerous animals, not easily tackled with muzzle-loaders. In a buffalo hunt in 1930 when, near the Kafue flats, a herd was driven, according to custom, into a selected swamp, the toll of dead was 30 buffalo and 7 of their native hunters. The amazing rapidity of the increase of this destructive species demands a planned effort at reducing their numbers and maintaining a constant check upon their increase. The same may be said about the elephant, of which there are at least 12,000 in Northern Rhodesia, and which are believed to have trebled in number during the past thirty years. Although there is no general excess, there are districts where the herds are rapidly becoming disturbingly large. The elephant must run no risk of extermination, but the cultivation and the works of man must also be considered. Based upon the rate of increase of the herds, which is estimated at 600 calves a year, Capt. Pitman suggests that control, exacting during the first three years up to a total of 800 individuals, could be organised in such a way that the herds of elephants at present roaming Northern Rhodesia would be shepherded into areas where there was the least chance of their interference with cultivation, and where their numbers could be kept at 
the highest level consistent with the welfare of the human population. He is of opinion that, in spite of the low price of ivory (in April 1934 the local African price was $6 s .6 d$. per lb.), the control could be carried out by the Government with an excess of revenue over expenditure.

On the much debated question of the relationship between game and the survival of the tsetse fly, Capt. Pitman makes no pronouncement, but he notes that there is a tendency for this noxious carrier of sleeping-sickness (Glossina morsitans) to be carried from infected to fly-free areas by mechanical transport along the roads, and as regards game in the fly-belts themselves his conclusion is surely a sound one in the interests of both mankind and wild stock. "In a sparingly populated country like Northern Rhodesia, where 'fly' belts predominate, precluding the possibility of the natives keeping the necessary stock for their meat requirements, it is a duty to the indigenous population--in the absence of a ' $\mathrm{fly}$ ' specific-to ensure the perpetuation of an adequate quantity of the wild animals from a dietetic point of view, if for no other ; and to this end must native opinion be educated."

To strike a just balance between the various interests of mankind and the survival of wild game is no easy matter, and while regulations regarding game licences and the control of game in general, by protection or limited destruction, are essential and helpful, the safety of wild animals in the future is bound up with the establishment and efficient policing of game reserves and national sanctuaries in regions of sparse population, where the promise of native interference is slightest and of permanency greatest.

J. R.

\section{Back to Minkowski}

\section{Relativity :}

an Elementary Explanation of the Space-Time Relations as established by Minkowski, and a Discussion of Gravitational Theory based thereon. By Dr. F. W. Lanchester. Pp. xiv + 222. (London : Constable and Co., Ltd., 1935.) 12s, net.

$\mathrm{D}^{\mathrm{n}}$ R. LANCHESTER, usually thought of in connexion with aerodynamics and motor engineering, has been interested in the theory of relativity since so far back as 1908 , when he met Minkowski soon after the well-known pronouncement that "henceforth space by itself and time by itself will fade to mere shadows, and only a kind of union of the two will remain". The object of the present book is to reconstruct and develop the theory anew, following Minkowski rather than Einstein, and replacing advanced mathematical methods such as the tensor calculus by elementary geometry and algebra, illustrated by a large number of diagrams. On several topics, such as the velocity of light, space curvature, and the expansion of the universe, Dr. Lanchester differs from the usual conclusions.

Chapters i-iv, dealing with the restricted theory, call for little comment. In Chapter $\mathrm{v}$ it is argued that the phenomena of the pressure of light and the diffusion of matter by radiation compel us to reject the usual doctrine that the velocity of light in a vacuum is equal to the limiting velocity which can never be exceeded (that is, the $c$ of the Lorentz formulae). Chapters vi-viii are described as an attempt to deal with gravitation on the basis of Minkowski's work. Planetary motion is treated by combining the Newtonian law of attraction with the FitzGerald contraction. The displacement of the Fraunhofer lines is deduced from the assumption that the time-rate of the 'solar chronometer' corresponds to that of an imaginary planet just skimming the sun's surface. This assumption gives half of Einstein's result. All that is claimed for this treatment of gravitation is that it gives results of the right kind and the right order of magnitude without making use of more than the most elementary algebraic expressions. It is acknowledged that space and time are dealt with separately, instead of together, and that the exposition lacks finality.

Chapters ix and $\mathrm{x}$ discuss some difficulties concerning the propagation of gravitation and the irregularities in the earth's rotation. In Chapter xii, the author disagrees with Einstein's principle of equivalence, which is considered as difficult to reconcile with the relativity theory of gravitation. It is suggested that the principle should be regarded as "no more than a scaffolding or temporary support, made use of by Einstein in the erection of his edifice, ultimately to be discarded". Chapters xi and xiii attack the theories of the expansion of the universe and general space-curvature. It is pointed out that 